\title{
A SURVEY ON IMPLICIT REQUIREMENTS MANAGEMENT PRACTICES IN SMALL AND MEDIUM-SIZED ENTERPRISES
}

\author{
Onyeka Emebo, Olawande Daramola, Charles Ayo
}

Preliminary communication

Effective requirements management that embraces both explicit and implicit aspects is a prerequisite for successful software development. Although different researchers and practitioners have identified the importance of implicit requirements (IMR) for overall successful outcome of software development, there is a need to correlate these theoretical assumptions about implicit requirements with the state of the practice. This paper empirically investigates the perception and handling of implicit requirements in small and medium-sized software organisations. The survey was undertaken through a web-based questionnaire to which 56 participants from 23 countries responded. The study found that critical organisational factors such as number of years in business of an organisation, the years of experience of an organisation in requirements engineering, and size of software development team have positive correlation with the perception and handling of implicit requirements within an organisation. It also recommends that a comparative evaluation of the existing support tools for implicit requirements is necessary in order to validate the potential of these tools to solve existing challenges, and determine gaps that still exist.

Keywords: empirical survey; implicit requirements; requirements engineering; requirements management; software organisations

Anketa o načinu upravljanja bezuvjetnim zahtjevima u malim i srednje malim poduzećima

Prethodno priopćenje

Učinkovito upravljanje zahtjevima koje uključuje i izričita i bezuvjetna motrišta pretpostavka je za uspješni razvoj softvera. Iako su razni istraživači i praktičari prepoznali važnost bezuvjetnih zahtjeva (implicit requirements - IMR) za opći uspjeh razvijenog softvera, potrebno je povezati te teorijske pretpostavke oko bezuvjetnih zahtjeva s postojećim stanjem. U radu se provodi empirijsko istraživanje o shvaćanju i provođenju bezuvjetnih zahtjeva u malim i srednje malim organizacijama koje se bave razvojem softvera. Provedena je anketa preko interneta na koju je stiglo 56 odgovora iz 23 zemlje. Analiza je pokazala da se kritički organizacijski čimbenici kao što su broj godina provedenih na poslu u nekoj organizaciji, godine iskustva organizacije u inženjeringu zahtjeva i veličina tima koji se bavi razvojem softvera pozitivno odražavaju na sagledavanje i pristup bezuvjetnim zahtjevima u okviru organizacije. Izražava se potreba za komparativnom procjenom postojećih alata podrške bezuvjetnim zahtjevima kako bi se potvrdio potencijal tih alata u rješavanju postojećih izazova i popunjavanju nedostataka koji još postoje.

Ključne riječi: bezuvjetni zahtjevi; empirijska anketa; inženjerstvo zahtjeva; organizacije koje se bave razvojem softvera; upravljanje zahtjevima

\section{Introduction}

The requirements of a software system are essential for effective performance of its functions and therefore effective requirements engineering is crucial for the success of software development projects [1].

From the perspective of requirements elicitation, requirements can be classified into explicit requirements (clearly stated requirements) and implicit or tacit requirements, which are assumed or unspoken requirements that are not stated or documented $[2,3]$. Implicit requirements (MR) have also been defined as non-verbalized customer expectations [2]. IMR can occur due to a number of reasons, which include:

- when implicit shared understanding of the quality of requirements is lacking among stakeholders in a project $[4,5]$;

- when the advent of tacit knowledge causes a knowledge gap between developers and shareholders in a project [6];

- when a software organisation is developing a product in a new domain; or a project has been subcontracted to external organisation that has a different operational background [7]; and

- when various forms of ambiguity exist in requirements that could lead to different incompatible interpretations of same set of requirements by different stakeholder groups $[8,9]$.

However, the hidden nature of IMR make them challenging to capture, in most cases, developers and testers rely on their own experience to manage them [1, 3]. IMR are as essential to the successful implementation and acceptance of the system by the user as explicit requirements. In [10], it was stated that the quality of software is dependent on the measure of its conformance to both explicit and implicit requirements. Authors in [11] also indicated that the quality of software cannot be adjudged good, and guaranteed to meet customer's satisfaction if only explicit requirements are satisfied while implicit requirements are ignored. Because of their relevance, different researchers have proposed different approaches, methods and tools to efficiently identify and manage IMR from different sources. These include [3, $12,13,14]$, which considered how to identify and handle IMR. The works in $[8,15,16,17,18]$ focussed on dealing with tacit/implicit knowledge in requirements; while [9, $19,20,21,22]$ dealt with handling ambiguity in requirements.

Although different researchers and practitioners have acknowledged the importance of IMR to the overall success of software development, there is yet the need to empirically investigate the way practitioners perceive them in terms of their real impact on the success or otherwise of software development and how they are managed by software organisations. Currently, not many empirical studies on the perception of IMR among practitioners and the way they are being handled in practice have been reported in the literature. This is the motivation for this study. The aim of this paper is to assess practitioner's perspective of IMR and identify the relationship between specific charactersitics of small and 
medium-sized software organisations and implicit requirements management practices. Therefore, the research question investigated in this work is: What are the factors that determine how IMR are handled in system development practice in small and medium-sized software organisations?

The rest of this paper is as follows: Section 2 previews related work; Section 3 describes the framework for developing the hypotheses in the study and the research methodology while Section 4 presents the analysis and results. In Section 5, we present a discussion of results, while Section 6 discusses the validity threats. The paper is concluded in Section 7 with a brief note.

\section{Related work}

Generally, the issue of management of IMR has gained some attention in the literature with researchers focusing on aspects that deal with identification and handling of implicit/tacit requirements. Efforts such as [3, 13] engaged analogy reasoning and ontology-based approaches for identification of implicit requirements. Some other researchers have focused on handling implicit requirements by dealing with tacit/implicit knowledge. Examples of these include [8, 15, 16, 17, 18]. Additionally, some researchers have attempted to tackle implicit requirements by resolving ambiguity in requirements specifications. Instances of these include $[19,20,21,22]$. However, so far in the literature, there are not many empirical studies that focussed specifically on the issue of implicit requirements within software organisations. The ongoing work reported in [23] was done to identify the impact of tacit and explicit knowledge transferred during software development projects. An inductive, exploratory, qualitative methodology was applied in order to validate the tacit knowledge spectrum in software development projects. The work aims to create a conceptual model that supports future software development projects in their tacit to explicit knowledge transfers. No concrete findings of the study was reported.

There are many studies that have addressed issues of requirements engineering within software organisations as a whole. For example in [24], the results of a diagnostic study of requirements engineering (RE) practices in very small software companies in Chile was presented. The study identified the state of the practice in these companies and the potential limitations that can hinder adoption of appropriate requirements engineering practices in the Chilean very small software enterprises. In [25] the report of an explorative study of software engineering practices in five small and medium-sized organisations was presented. Although the work did not focus particularly on RE practices, the study reveals interesting issues about software development practices in small organisations. In [26], a report of RE practices in seven very small scale enterprises (VSSE) in Canada was presented. The exploratory study found that RE practices in VSSE were diverse and are being successfully applied, the organisations engaged experienced personnel in charge of their RE processes, requirements errors were rarely severe, and the organisations had strong cultural orientations. In [27] authors identified critical factors that affect organisation-wide implementation of RE processes. The work was based on a broad literature review and three longitudinal case studies that were carried out using action research. In [28], a study of the current RE practices, development needs and preferred ways of technology transfer of twelve small to medium-sized companies in Finland was reported. The study gave attention to the level of adoption for several RE practices and degree of adherence to general guidelines for RE practices.

Other surveys or field studies that focussed on requirements engineering practices in software organisations include [29] - requirements modelling; [30, $31,32,33]$ - adoption of standard RE practices; [34, 35] intelligent assistance; and [36, 37] - variability management. What is of note is that none of these previous empirical studies have focussed specifically on the management and handling of implicit requirements as we have done in this study.

\section{Research methodology and hypotheses development}

In this section, we discuss the framework that is used to investigate the factors influencing implicit requirements management during software development process as well as the research methodology used. The six factors that were used as basis for hypotheses development is shown in Fig. 1. Also, the description of the framework is shown in Tab. 1.

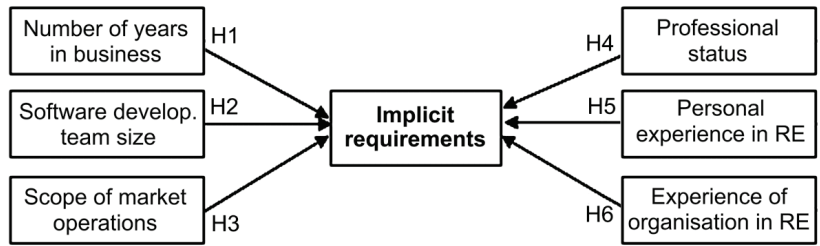

Figure 1 Framework for hypothesis development

Table 1 Factors influencing IMR management

\begin{tabular}{|c|c|c|}
\hline S/no & Factor & Description \\
\hline 1 & $\begin{array}{c}\text { Number of years in } \\
\text { business }\end{array}$ & $\begin{array}{c}\text { Number of years that company has } \\
\text { been in business }\end{array}$ \\
\hline 2 & $\begin{array}{c}\text { Software development } \\
\text { team size }\end{array}$ & $\begin{array}{c}\text { The number of persons in the } \\
\text { development team }\end{array}$ \\
\hline 4 & $\begin{array}{c}\text { Scope of market } \\
\text { operations }\end{array}$ & $\begin{array}{c}\text { If the company's operational market } \\
\text { can be classified as local, } \\
\text { international or both }\end{array}$ \\
\hline 5 & $\begin{array}{c}\text { Professional status } \\
\text { RE }\end{array}$ & $\begin{array}{c}\text { The status of a respondent within an } \\
\text { organisation, be it junior level, } \\
\text { middle level or management level. }\end{array}$ \\
\hline 6 & $\begin{array}{c}\text { Experience of } \\
\text { organisation in RE }\end{array}$ & Expertise of the organisation in RE \\
\hline
\end{tabular}

\subsection{Research methodology}

For the purpose of this study, a web-based questionnaire was designed. This questionnaire contained closed ended questions. The sampled population for the empirical study were software developers from small and medium-sized companies in different countries. The questionnaire was designed as a tool to investigate the perception of implicit requirements, and how they are managed by small and medium-sized software organisations. We focused more on small and medium- 
sized software organisations because they are more in number and easily accessible compared to large-sized organisations. The objective of the survey is to understand the extent of consideration that is given to implicit requirements in practice in the course of software development. An overview of the adopted research process is presented in Fig. 2.

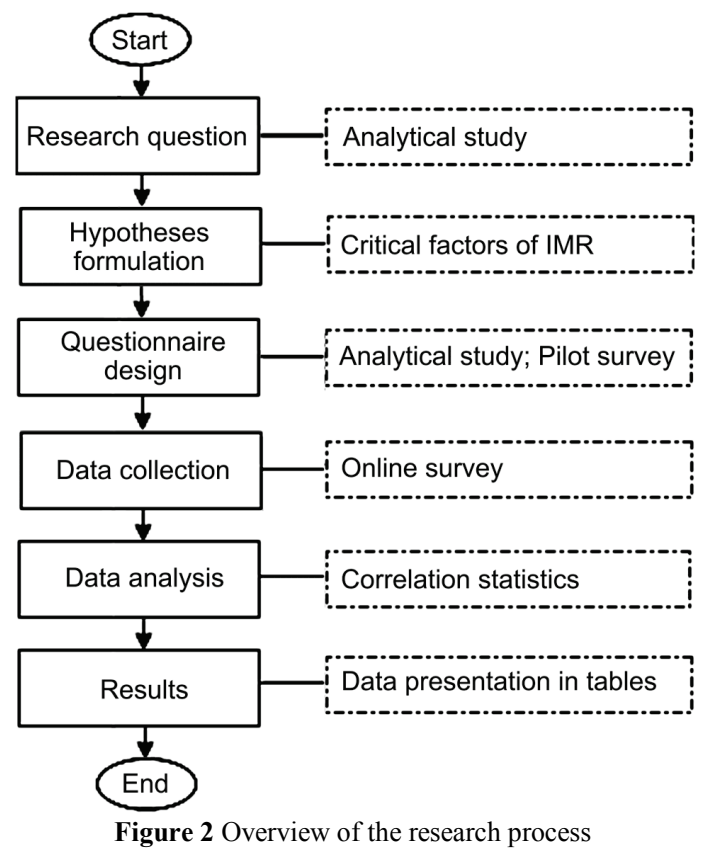

\subsection{Structure of survey}

The questionnaire is two-paged and contains two sections. The first section contained introductory questions on the name of country (where the company is based), name of respondents' company, background information on the organisation and professional background of the respondent. This section was used to gain information about the respondent's experience in RE, and also the organisation's experience in RE in terms of number of years. The second section contained closeended questions to elicit information on the perception of implicit requirements within the respondent's organisation and how they are managed. The questions in this section seek to know the relevance attached to implicit requirements in a respondent's organisation during the process of developing software.

\subsection{Data collection method}

A web-based questionnaire was used to draw participation of diverse respondents from different parts of the world. We made an open call through survey invites in relevant online requirements engineering and software engineering communities such as Yahoo Requirements Engineering Group, Linked-in Requirements Engineering Specialist group (RESG), and Requirements Engineering Conference mailing list, AISWorld, and SEWORLD. This is to ensure that interested and qualified persons from these communities that have diversified global memberships are notified of the survey. We also made direct contact with a few local companies in Nigeria, and some of academic colleagues that are based in Europe and the US to help disseminate information about the survey. Many of them did this, by sending email invites to their colleagues within the software engineering community. The survey was online for a period of 6 months. At the end, we got the 56 respondents that participated, with respondents from countries such as Australia (2), Austria (3), Brazil (2), Chile (1), Germany (4), India (5), Ireland (1), Israel (2), Italy (2), Macedonia (1), New Zealand (2), Norway (2), Poland (1), Serbia (1), Sweden (1), United States of America (9), United Kingdom (4), Yugoslavia (1), Afghanistan (1), Spain (3), Netherland (3), Canada (3) and Nigeria (2). The data collected from the online survey formed the basis of our analysis. The survey questions and data are available at [38]. All of the respondents claimed to be software developers, with majority specialising in development of business and enterprise software solutions.

\subsection{Test method}

The major test that was carried out in this study is the correlation analysis test using the Spearman's rank correlation coefficient (Spearman's rho). We used this to test the six hypotheses that we formulated. For each hypothesis, we used the correlation analysis technique to determine the relationship between certain factors/characteristics of the respondents and their responses to the close-ended questions in the questionnaire. We investigated whether the six factors/characteristics have any significant impact on the perception and handling of implicit requirements. If so, how strong is the relationship? Below are the formulated Hypotheses:

H1: Number of years in business has significant relationship with the knowledge and views of an organisation on implicit requirements.

H2: Size of software development team of an organisation has significant impact on the knowledge and handling of implicit requirements

H3: The organisation's scope of market operation has significant impact on its knowledge and views on implicit requirements

H4: Professional status of an employee in an organisation has significant impact on his/her knowledge and views of implicit requirements.

H5: Years of personal experience of an individual in $\mathrm{RE}$ has significant impact on the knowledge and views of implicit requirements.

H6: Experience of an organisation in RE has significant impact on its knowledge and handling of implicit requirements.

\section{Analysis and results \\ 4.1 Background of respondents}

There were 56 respondents $(n=56)$ from different parts of the world. The data on the background of respondents as it pertains to the six factors is presented in Tab. 1. Also, Tab. 2 shows that a larger number of the respondents work for companies with over 20 years' experience $(46,4 \%)$ in software development business, 
while a $89,3 \%$ of the sampled population have more than 5 years experience in software development.

Table 2 Data on characteristics of respondents

\begin{tabular}{|c|c|c|}
\hline $\mathrm{S} / \mathrm{No}$ & Factor & Analysis \\
\hline 1 & $\begin{array}{l}\text { Years of business } \\
\text { (years) }\end{array}$ & $\begin{array}{l}>20 \text { yrs }=26(46,4 \%) \\
16 \div 20 \text { yrs }=6(10,7 \%) \\
11 \div 15 \text { yrs }=9(16,1 \%) \\
6 \div 10 \text { yrs }=9(16,1 \%) \\
0 \div 5 \text { yrs }=6(10,7 \%)\end{array}$ \\
\hline 2 & $\begin{array}{l}\text { Software development } \\
\text { team size } \\
\text { (persons) }\end{array}$ & $\begin{array}{l}>50=10(17,9 \%) \\
21 \div 50=5(8,9 \%) \\
16 \div 20=6(10,7 \%) \\
11 \div 15=9(16,1 \%) \\
6 \div 10=8(14,3 \%) \\
0 \div 5=18(32,1 \%)\end{array}$ \\
\hline 3 & $\begin{array}{l}\text { Scope of market } \\
\text { operation }\end{array}$ & $\begin{array}{l}\text { Local = } 24(42,9 \%) \\
\text { International }=11(19,6 \%) \\
\text { Both }=21(37,5 \%)\end{array}$ \\
\hline 4 & $\begin{array}{l}\text { Professional status of } \\
\text { respondent's within } \\
\text { their organisation }\end{array}$ & $\begin{array}{l}\text { Management level }=19(33,9 \%) \\
\text { Middle level }=35(62,5 \%) \\
\text { Lower level }=2(3,6 \%)\end{array}$ \\
\hline 5 & $\begin{array}{l}\text { Respondent's years of } \\
\text { experience in RE }\end{array}$ & $\begin{array}{l}>20 \text { yrs }=15 \% \\
16 \div 20 \text { yrs }=2 \% \\
11 \div 15 \text { yrs }=21 \% \\
6 \div 10 \text { yrs }=34 \% \\
0 \div 5 \text { yrs }=28 \%\end{array}$ \\
\hline 6 & $\begin{array}{l}\text { Experience of the } \\
\text { organisation in RE }\end{array}$ & $\begin{array}{l}>20 \text { yrs }=18(32,1 \%) \\
16 \div 20 \text { yrs }=5(8,9 \%) \\
11 \div 15 \text { yrs }=9(16,1 \%) \\
6 \div 10 \text { yrs }=14(25 \%) \\
0 \div 5 \text { yrs }=10(17,9 \%)\end{array}$ \\
\hline
\end{tabular}

\subsection{Software team development size}

Of the respondents, $19,6 \%$ came from companies that have international scope of operation, $42,9 \%$ from companies with local scope of operation, while $37,5 \%$ described the operational scope of their company as both local and international (see Tab. 2). In terms of professional status of respondents, 33,9\% belong to the managerial level, 62,5\% to middle career level, while 3,6 $\%$ belong to the lower level. This shows that there is a greater population of middle level personnel amongst the respondents compared to management and junior level employees. In terms of experience in RE, $41 \%$ of respondents' organisations have at least 15 years of experience in RE, while $38 \%$ of respondents claimed to have more than 10 years experience in RE practice.

\subsection{Reliability test}

We conducted reliability test in order to measure the consistency and stability of the data used for the analysis. We used the Cronbach's Alpha Test to determine the reliability of the data used in this study. According to [39], Cronbach's alpha is a reliability test measure involving only one test administration to provide a given test with a unique evaluation. It is represented by the symbol $\alpha$. During the process of establishing content validity of the questionnaire, we conducted pilot survey using a few experts, who acted as respondent in order to review the questions and offer suggestions for improvement. The revised questionnaire and additional suggested questions were used in the survey instrument. The data collected is reliable under the Cronbach's Alpha test when $\alpha$ has a minimum of 0,7 . For this study, the Cronbach's Alpha Test is valued at 0,783. This indicates that the data collected from the set questionnaire is suitable for carrying out further test and analysis.

Table 3 Reliability test table
\begin{tabular}{|c|c|}
\hline \multicolumn{2}{|c|}{ Reliability statistics } \\
\hline Cronbach's Alpha & N of items \\
\hline 0,783 & 23 \\
\hline
\end{tabular}

\subsection{Hypothesis testing \\ 4.3.1 Correlation analysis}

For this study, Spearman Correlation Analysis was adopted to determine the impact of the six selected factors on the knowledge and perception of implicit requirements by software developers. The aim was to determine if certain factors have significant influence or relationship with the knowledge and perception of implicit requirements. The Spearman's correlation coefficient is a statistical measure of the strength of a monotonic relationship between two variables. It is represented by the spearman's rho ( $r s)$. In this research, the selected factors were tested against the questions. However the tables below reflect responses, which show the questions with significant relationship with the respective factor and all non-significant responses were excluded.

\section{a) Number of years in business}

H1: Number of years in business has significant relationship with the knowledge and view of implicit requirements

$\mathrm{H} 1_{\mathrm{o}}$ : Number of years in business has no significant impact on the knowledge and view of implicit requirements

The number of years in business represents the number of years in the practice of software development by a company. From the result extracted as shown in table 4 the questions with significant relationship are as listed below. Although there were a few significant relationships, they were however weak not exceeding 0.4 . This means that there exists significant influence although it is not very strong.

Where:

Q 2.7.1. A specialised approach, possibly with some automation support will be useful for managing implicit requirements $(0,296)$

Q 2.14. Established RE management methods are adequate to handle implicit requirements for now $(0,295)$

Q 2.6. Using experience plus tool support will be perfect for managing implicit requirements $(0,379)$

$\mathrm{Q}$ 2.4. Implicit requirements do not have any impact on correctness of system architecture $(0,295)$

Q2.3. Implicit requirements do not have any effect on the acceptability of software product $(0,344)$

Tab. 4 shows that although the number of years in the business of software engineering has some effect on the knowledge and view of implicit requirements, there are other factors that affect the knowledge and perception of how implicit requirements should be handled in an organisation. The results of the analysis show that the greater the number of years in business the better the knowledge and perception of implicit requirements. This means that those with longer years in the business have a 
lot more regard for the subject of implicit requirements. It also shows that they recognise the need for improvement in the way implicit requirements are handled and its importance to the functionality of the developed system. Hence, $\mathrm{H} 1$ is accepted.

Table 4 Result of correlation testing for $\mathrm{H} 1$

\begin{tabular}{|c|c|c|c|}
\hline & & & $\begin{array}{l}\text { No. of years in } \\
\text { business }\end{array}$ \\
\hline \multirow{15}{*}{$\begin{array}{l}\text { Spearman's } \\
\text { rho }\end{array}$} & \multirow[t]{3}{*}{ Q 2.14 . } & Correlation Coefficient & $0,295 *$ \\
\hline & & Sig. (2-tailed) & 0,027 \\
\hline & & $N$ & 56 \\
\hline & \multirow[t]{3}{*}{ Q 2.7.1. } & Correlation Coefficient & $0,296^{*}$ \\
\hline & & Sig. (2-tailed) & 0,027 \\
\hline & & $N$ & 56 \\
\hline & \multirow[t]{3}{*}{ Q 2.6. } & Correlation Coefficient & $0,379 * *$ \\
\hline & & Sig. (2-tailed) & 0,004 \\
\hline & & $N$ & 56 \\
\hline & \multirow[t]{3}{*}{ Q2.3. } & Correlation Coefficient & $0,344 * *$ \\
\hline & & Sig. (2-tailed) & 0,009 \\
\hline & & $N$ & 56 \\
\hline & \multirow[t]{3}{*}{ Q 2.4. } & Correlation Coefficient & $0,325^{*}$ \\
\hline & & Sig. (2-tailed) & 0,014 \\
\hline & & $N$ & 56 \\
\hline
\end{tabular}

\section{b) Size of software development team}

H2: Size of software development team has significant impact on the knowledge and handling of implicit requirements

$\mathrm{H} 2_{\mathrm{o}}$ : Size of software development team has no significant impact on the knowledge and handling of implicit requirements

The size of software development teams differs per company depending on the size of the organisation. In many instances, the larger the organisation, the larger the work load, and hence the need for a large software development team. The result of the analysis showed that the size of the software development team had a significant impact on the perception and knowledge of implicit requirements. However, these relationships are not very strong as none of the correlation coefficient exceeded 0,5 as shown in Tab. 5 .

\begin{tabular}{|c|c|c|c|}
\hline & & & $\begin{array}{l}\text { Size of software } \\
\text { development } \\
\text { team }\end{array}$ \\
\hline \multirow{15}{*}{$\begin{array}{l}\text { Spearman's } \\
\text { rho }\end{array}$} & \multirow[t]{3}{*}{ Q 2.8. } & Correlation Coefficient & $-0,288^{*}$ \\
\hline & & Sig. (2-tailed) & 0,031 \\
\hline & & $N$ & 56 \\
\hline & \multirow[t]{3}{*}{ Q 2.14. } & Correlation Coefficient & $0,271 *$ \\
\hline & & Sig. (2-tailed) & 0,043 \\
\hline & & $N$ & 56 \\
\hline & \multirow[t]{3}{*}{ Q 2.3. } & Correlation Coefficient & $0,384 * *$ \\
\hline & & Sig. (2-tailed) & 0,003 \\
\hline & & $N$ & 56 \\
\hline & \multirow[t]{3}{*}{ Q 2.4. } & Correlation Coefficient & $0,343 * *$ \\
\hline & & Sig. (2-tailed) & 0,010 \\
\hline & & $N$ & 56 \\
\hline & \multirow[t]{3}{*}{ Q 2.13. } & Correlation Coefficient & $0,308^{*}$ \\
\hline & & Sig. (2-tailed) & 0,021 \\
\hline & & $N$ & 56 \\
\hline
\end{tabular}

Where:

Q 2.8. Improper handling of implicit requirements can lead to poor system design and poor product performance $(-0,288)$

Q 2.14. Established RE management methods are adequate to handle implicit requirements for now $(0,271)$

$\mathrm{Q}$ 2.3. Implicit requirements do not have any effect on the acceptability of software product $(0,384)$

Q 2.4. Implicit requirements do not have any impact on correctness of system architecture $(0,343)$

$\mathrm{Q}$ 2.13. There is no need to evolve new methods to specially handle implicit requirements $(0,308)$

The size of the software development team shows a positive correlation with questions Q 2.14, Q 2.3, Q 2.4, Q 2.13 with the exception of Q 2.8, which had a negative value of $(-0,288)$. This connotes that with increase in the size of software development team the negative impact of implicit requirements on correctness of system architecture, acceptability of software product will be reduced. Also, established RE methods will become more adequate to handle implicit requirements, while reducing the size of software development team will increase improper handling of implicit requirements. From this analysis, it can be inferred that although the size of the software development team has significant impact on the perception and handling of implicit requirements, there are other factors that also play a role since the values are closer to zero than to +1 , which is a perfect positive correlation. Therefore, $\mathrm{H} 2$ is selected.

\section{c) Level of market operation}

H3: The organisation's scope of market operation has significant impact on the knowledge and view of implicit requirements

$\mathrm{H} 3_{\mathrm{o}}$ : The organisation's scope of market operation has no significant impact on the knowledge and view of implicit requirements

From the analysis conducted, the level of operation was classified based on the type of target market, which is local, global and both local and global. A larger percentage of the population of the respondents operate at either local level or at both local and global levels. The analysis showed that the target market of the company or level of operation of the organisation has no significant impact on the views and knowledge of implicit requirements. Hence, there is no table showing any significance relationship between any of the question, therefore $\mathrm{H} 3$ is rejected and $\mathrm{H} 3{ }_{\mathrm{o}}$ is selected.

\section{d) Professional status in organisation}

H4: Professional Status of an employee in an Organisation has significant impact on the knowledge and view of implicit requirements

$\mathrm{H}_{4}$ : Professional Status of an employee in an Organisation has no significant impact on his/her knowledge and views of implicit requirements.

The professional status of an employer within an organisation has been categorized into three levels. These are the Junior Level, Middle Level and Managerial Level. The analysis result in Tab. 6 showed that there was only one significant relationship between one of the questions and the professional status. 
Table 6 Result of correlation testing for $\mathrm{H} 4$

\begin{tabular}{|c|c|c|c|c|}
\hline & & & Q 8. & Q 2.5. \\
\hline \multirow{6}{*}{$\begin{array}{l}\text { Spearman's } \\
\text { rho }\end{array}$} & \multirow[t]{3}{*}{ Q 8. } & Correlation Coefficient & 1,000 & $0,347 * *$ \\
\hline & & Sig. (2-tailed) & 0,0 & 0,009 \\
\hline & & $N$ & 56 & 56 \\
\hline & \multirow[t]{3}{*}{ Q 2.5. } & Correlation Coefficient & $0,347 * *$ & 1,000 \\
\hline & & Sig. (2-tailed) & 0,009 & 0,0 \\
\hline & & $N$ & 56 & 56 \\
\hline
\end{tabular}

Where:

Q8. Your professional status in your organisation.

Q2.5. Relying principally on experience is sufficient for the discovery of implicit requirements during requirements elicitation $(0,347)$.

The result of the analysis showed that the higher the professional status, the greater the disagreement with the statement or close ended question. This means that those that are higher up in the career hierarchy do not believe that experience alone is sufficient for the discovery of implicit requirements. Although they agree that experience plays an important role, other approaches are required. Therefore, $\mathrm{H} 4$ is selected.

\section{e) Years of personal experience in RE}

H5: Years of personal experience in RE has significant impact on the knowledge and view of implicit requirements

$\mathrm{H}_{5}$ : Years of personal experience in $\mathrm{RE}$ has no significant impact on the knowledge and view of implicit requirements.

The result of the analysis showed that years of personal experience in RE had significant impact on some of the responses to the close-ended questions. These questions include the following:

Q 8. Your experience in Requirements Engineering (RE) practice in terms of years

Q 2.5. Relying principally on experience is sufficient to the discovery of implicit requirements during requirements elicitation $(0,290)$

Q 2.6. Using experience plus tool support will be perfect for managing implicit requirements $(0,365)$

Q 2.14. Established RE management methods are adequate to handle implicit requirements for now $(0,263)$

Q 2.3. Implicit requirements do not have any effect on the acceptability of software product $(0,291)$.

Table 7 Result of correlation testing for H5

\begin{tabular}{|c|c|c|c|}
\hline & & & Q 8. \\
\hline \multirow{12}{*}{$\begin{array}{l}\text { Spearman's } \\
\text { rho }\end{array}$} & \multirow[t]{3}{*}{ Q 2.5. } & Correlation Coefficient & $0,290^{*}$ \\
\hline & & Sig. (2-tailed) & 0,030 \\
\hline & & $N$ & 56 \\
\hline & \multirow[t]{3}{*}{ Q 2.6. } & Correlation Coefficient & $0,365 * *$ \\
\hline & & Sig. (2-tailed) & 0,006 \\
\hline & & $N$ & 56 \\
\hline & \multirow[t]{3}{*}{ Q 2.3. } & Correlation Coefficient & $0,291 *$ \\
\hline & & Sig. (2-tailed) & 0,030 \\
\hline & & $N$ & 56 \\
\hline & \multirow[t]{3}{*}{ Q 2.14. } & Correlation Coefficient & $0,263^{*}$ \\
\hline & & Sig. (2-tailed) & 0,050 \\
\hline & & $N$ & 56 \\
\hline
\end{tabular}

This analysis showed that although there is a significant relationship, it is however not strong as the coefficients are closer to 0 than +1 , which is an indicator of a perfect positive correlation. The analysis in Tab. 7 shows that developers with longer years of experience have more regard and understanding of the implicit requirements. This could be due to many practical cases of implicit requirements that they have handled in the course of their career. Therefore, H5 is selected.

\section{f) Experience of the organisation in RE}

H6: Experience of an Organisation in RE has significant impact on the knowledge and view of implicit requirements

$\mathrm{H6}_{\mathrm{o}}$ : Experience of an Organisation in RE has no significant impact on the knowledge and view of implicit requirements.

Q 9. Experience of your organisation in $R E$.

Table 8 Result of correlation testing for H6

\begin{tabular}{|c|c|c|c|}
\hline & & & Q 9. \\
\hline \multirow{21}{*}{$\begin{array}{l}\text { Spearman's } \\
\text { rho }\end{array}$} & \multirow[t]{3}{*}{ Q 2.13. } & Correlation Coefficient & $0,297^{*}$ \\
\hline & & Sig. (2-tailed) & 0,026 \\
\hline & & $N$ & 56 \\
\hline & \multirow[t]{3}{*}{ Q 2.14. } & Correlation Coefficient & $0,397 * *$ \\
\hline & & Sig. (2-tailed) & 0,002 \\
\hline & & $N$ & 56 \\
\hline & \multirow[t]{3}{*}{ Q 2.15. } & Correlation Coefficient & $0,387 * *$ \\
\hline & & Sig. (2-tailed) & 0,003 \\
\hline & & $N$ & 56 \\
\hline & \multirow[t]{3}{*}{ Q 2.3. } & Correlation Coefficient & $0,301^{*}$ \\
\hline & & Sig. (2-tailed) & 0,024 \\
\hline & & $N$ & 56 \\
\hline & \multirow[t]{3}{*}{ Q 2.4. } & Correlation Coefficient & $0,314^{*}$ \\
\hline & & Sig. (2-tailed) & 0,018 \\
\hline & & $N$ & 56 \\
\hline & \multirow[t]{3}{*}{ Q 2.5. } & Correlation Coefficient & $0,293^{*}$ \\
\hline & & Sig. (2-tailed) & 0,028 \\
\hline & & $N$ & 56 \\
\hline & \multirow[t]{3}{*}{ Q. 2.6. } & Correlation Coefficient & $0,373 * *$ \\
\hline & & Sig. (2-tailed) & 0,005 \\
\hline & & $N$ & 56 \\
\hline
\end{tabular}

The analysis showed that the level/years of experience of an Organisation in RE have impact on the knowledge and perception of implicit requirements. The results as shown in Tab. 8 show that the years of experience of the Organisation had a significant influence on 7 out of the 17 questions. They include the following:

Q 2.5. Relying principally on experience is sufficient to the discovery of implicit requirements during requirements elicitation $(0,293)$

Q 2.6. Using experience plus tool support will be perfect for managing implicit requirements $(0,373)$

Q 2.14. Established RE management methods are adequate to handle implicit requirements for now $(0,397)$

Q 2.3. Implicit requirements do not have any effect on the acceptability of software product $(0,301)$

$\mathrm{Q}$ 2.4. Implicit requirements do not have any impact on correctness of system architecture $(0,314)$

Q 2.15. During requirements elicitation, stakeholders deliberately withhold certain information, which creates implicit requirements scenarios $(0,387)$

$\mathrm{Q}$ 2.13. There is no need to evolve new methods to specially handle implicit requirements $(0,297)$.

The results of the analysis show that companies with longer years of experience in RE acknowledge the importance of implicit requirements, regard them as 
crucial to the functionality of a system, and that they have effect on the consumer satisfaction. Although there is a significant relationship, the relationship is however not a strong one as it is below 0,5. With the correlation coefficients closer to zero, this indicates a weak relationship. This implies there are other factors, which play a major role in the knowledge, understanding and view of implicit requirements. Hence, H6 is selected.

\section{Discussion}

Based on the outcome of the analysis of the result of the survey, we can identify four salient issues, which we shall now discuss. First, we observed that there are critical organisational factors such as number of years in business of an organisation, and the years of experience of an organisation in dealing with RE, and size of software development team that have positive correlation with the views, and handling of implicit requirements within an organisation. From this, we can safely argue that the level of maturity of the software process in an organisation will affect the way implicit requirements are managed, although high maturity of software process may not automatically translate to handling implicit requirements the right way because of existence of other factors. Also, the scope of operation of an organisation whether local or global is a key determinant factor of how well an organisation handles implicit requirements. Second, there are critical human factors such as general professional experience of employees, and the level of experience in $\mathrm{RE}$ that determines the way implicit requirements are perceived and managed within an organisation. Therefore, we can speculate that organisations that have persons with significant professional experience in software development and RE in managerial positions, and also a significant bunch of these types of personnel in mid-level positions are more likely to perform better in terms of handling of implicit requirements than those where this is not the case.

The result of this survey also points to the fact that although so far the use of experience has played significant role in handling implicit requirements, a significant number of practitioners believe that additional means that can complement the use of experience such as tool support are necessary. Interestingly, but contrariwise, there also exists a significant number of practitioners that believe that existing requirements management tools are sufficient to handle implicit requirements for now, if maximized, and there is no need for new tools. In addition, there is a consensus that implicit requirements are real, and that many deliberate situations caused by users that lead to the emergence of implicit requirements exist.

The findings from our survey, which we have presented above, reveal a number of issues and claims by respondents that need empirical verification by the requirements engineering community. For example, it will be interesting to ascertain the strength of specific RE tools to manage implicit requirements in terms of addressing specific concerns across the RE lifecycle such as discovery of hidden requirements, analysing implicitness, traceability, prioritization and change impact analysis of implicit requirements. Also, a comparative evaluation of the existing support tools for implicit requirements is necessary in order to validate the potential of these tools to solve existing challenges and ascertain gaps that still exist.

\section{Validity threats}

The results obtained in this empirical study need to be understood within the strengths and limitations of the selected research methodology. Hence, in this section we explain how this research addressed specific validity threats.

Conclusion Validity: this refers to whether we can draw the right conclusions about the relationship treatment and the result obtained from the survey. Some of the concerns addressed in this aspect of validity are:

Low statistical power: In a highly technical domain such as requirements management, having a large number of respondents is not so much of a strength as identifying persons that are truly knowledgeable on the issue of managing implicit requirements. The 56 respondents that are located in 38 distinct organisations and across 23 countries is sufficient for a small scale empirical study that seeks to give a first empirically based opinion on the handling of implicit requirements in small and mediumsized software organisations. The open call made to members of relevant online communties also allowed persons who are knowledgeable and interested in issues of IMR to participate.

Reliability of measure: the spearman's correlation coefficient that was used to investigate the relationship between the variables in the stated hypotheses $(\mathrm{H} 1 \div \mathrm{H} 6)$ is a standard statistical measure that is suitable for the task it was used to perform. Also, in order to enhance the reliability of the measuring instrument, a pilot survey was conducted initially, which improved the quality of questions.

Reliability of treatment: all respondents had the same kind of information. The questions were in English, which happens to be the main language for business in the respondents' organisations despite their different cultural contexts.

Construct validity: this refers to the extent to which the operational measures that are studied truly represent the theoretical constructs on which those operational measures were based [40]. To achieve this, all respondents had the same instructions as guide for completing the questionnaire. The task was the same for all respondents who completed the online questionnaire. Hence, the results obtained from the survey depend on only one variable, which eliminates any mono-method bias effect.

Internal Validity: this refers to whether other factors other than the treatment influenced the outcome of the survey. For the survey, all respondents were software practitioners who claimed to have ample experience in requirements engineering. The bulk of participants were recruited from professional online communities such as Linkedin Requirement Engineering Specialist Group (RESG), Yahoo Requirements Engineering Group, SEWORLD and AISWORLD. Generally, the respondents have significant experience in RE with $38 \%$ having more than 10 years experience, while $72 \%$ have above 5 year 
experience in RE. Also, they were given sufficient background introduction, which they had to read before the questions were presented to them. Considereing the level of expertise in RE claimed by the respondents, we can conclude that issues such as difference in cultural contexts, gender and other social factors did not have significant influence on the findings of this study.

External Validity: The key interest of this aspect of validity is whether we can generalise the outcome of the survey to a larger context. The respondents were mostly experienced software engineers, who have practical experience on issues that deal with implicit requirements, and located in different parts of the world. A concern could be that possibly the result would have been different if a larger pool of qualified respondents was used for the survey. However, we waited six months to have the 56, it could not be ascertained if the number would have been significantly more if we had waited for a longer time since the call was made to everyone on the mailing lists of these online communities. Although we do not consider this as a major threat to the reliability of the outcome of this survey, an interesting point for future study is to have a wider group of requirements engineers participate in the survey.

In summary, we do not see any serious threats to the validity of our conclusions from the survey. Also, the fact that no other empirical study so far has looked specifically at the issue of implicit requirements in small and medium-sized software organisations makes the outcome of this study potentially valuable to practitioners.

\section{Conclusion}

In this paper, we have reported findings from a survey of implicit requirements management practices in small and medium-sized organisations. As a contribution, this paper presents a pioneering effort that is aimed at providing an understanding of implicit requirements management practices in small and medium-sized organisations based on empirical investigation. The survey results revealed that organisational experience in terms of age in business, experience in RE, and experience of personnel in RE, and software team size have positive correlation with effective management of implicit requirements within an organisation. The study also revealed that although use of experience has played significant role so far, the need for tool support is also desirable for better handling of implicit requirements. However, significant number of practitioners believe that existing RE tools are equally sufficient for managing implicit requirements if they are maximized, and there is no need for new tools. We can deduce from the study that there is a need to promote general understanding of implicit requirements and the need for more significant interest in issues of implicit requirements compared to explicit requirements, which have received the most attention in the literature.

For future work, this study found a number of issues, which should stimulate future empirical investigations. These include the need to evaluate the capability of existing RE management tools for managing implicit requirements, and the potentials of existing automated tools so far proposed in literature to support management of implicit requirements throughout the RE lifecycle.

\section{Acknowledgement}

The research was supported by the Covenant University Centre for Research, Innovation and Development (CUCRID).

\section{References}

[1] Skoković, P.; Rakić-Skoković, M. Requirements-Based Testing Process in Practice. // International Journal of Industrial Engineering and Management (IJIEM). 1, 4(2010), pp. 155-161.

[2] Lauesen, S.; Vinter, O. Preventing requirement defects: An experiment in process improvement. // Requirements Engineering. 6, 1(2001), pp. 37-50. DOI: 10.1007/PL00010355

[3] Daramola, O.; Moser, T.; Sindre, G.; Biffl, S. Managing implicit requirements using semantic case-based reasoning research preview. // In International Working Conference on Requirements Engineering: Foundation for Software Quality / Springer Berlin Heidelberg, 2012, pp. 172-178.

[4] Glinz, M. A Risk-based Value-oriented Approach to Quality Requirements. // IEEE Software. 2 (2008), pp. 3441. DOI: $10.1109 / \mathrm{MS} .2008 .31$

[5] Glinz, M.; Fricker, S. A. On shared understanding in software engineering: an essay. // Computer ScienceResearch and Development. 30, 3-4(2015), pp. 363-376.

[6] Stone, A.; Sawyer, P. Identifying tacit knowledge-based requirements. // IEE Proceedings-Software. 153, 6 (2006), pp. 211-218. DOI: 10.1049/ip-sen:20060034

[7] Deshpande, S.; Richardson, I. Management at the Outsourcing Destination-Global Software Development in India. // In 2009 Fourth IEEE International Conference on Global Software Engineering. IEEE, 2009, pp. 217-225. DOI: 10.1109/ICGSE.2009.29

[8] Gacitua, R.; Ma, L.; Nuseibeh, B.; Piwek, P.; De Roeck, A. N.; Rouncefield, M.; Sawyer, P.; Willis, A.; Yang, H. Making Tacit Requirements Explicit. // In IEEE Second International Workshop on Managing Requirements Knowledge (MARK). IEEE, 2009, pp. 40-44.

[9] Chantree, F.; Nuseibeh, B.; De Roeck, A.; Willis, A. Identifying nocuous ambiguities in natural language requirements. $/ /$ In $14^{\text {th }}$ IEEE International Requirements Engineering Conference (RE'06). IEEE, 2006, pp. 59-68. DOI: 10.1109/RE.2006.31

[10] Ahamed, R. An Integrated and Comprehensive Approach to Software Quality. // International Journal of Engineering Science and Technology. 2, 2(2010), pp. 59-66.

[11] Drysdale, D. High-Quality Software Engineering. 2007, http://www.lurklurk.org/hqse.pdf (01/10/2012)

[12] Arts, T.; Dorigatti, M.; Tonetta, S. Making implicit safety requirements explicit. // In Computer Safety, Reliability, and Security. Springer International Publishing, 2014, pp. 81-92. DOI: 10.1007/978-3-319-10506-2 6

[13] Emebo, O.; Olawande, D.; Charles, A. An automated tool support for managing implicit requirements using Analogybased Reasoning. // In IEEE Tenth International Conference on Research Challenges in Information Science (RCIS). IEEE, 2016, pp. 1-6. DOI: 10.1109/rcis.2016.7549329

[14] Gervasi, V.; Zowghi, D. Mining requirements links. // In International Working Conference on Requirements Engineering: Foundation for Software Quality. Springer Berlin Heidelberg, 2011, pp. 196-201 .

[15] Olmos, K.; Rodas, J. KMoS-RE: knowledge management on a strategy to requirements engineering. // Requirements 
Engineering. $\quad 19,4$ (2014), pp. 421-440. DOl: 10.1007/s00766-013-0178-3

[16] Gervasi, V.; Gacitua, R.; Rouncefield, M.; Sawyer, P.; Kof, L.; Ma, L.; ... Nuseibeh, B. Unpacking tacit knowledge for requirements engineering. // In Managing requirements knowledge. Springer Berlin Heidelberg, 2013, pp. 23-47. DOI: 10.1007/978-3-642-34419-0_2

[17] Stoiber, R.; Glinz, M. Modeling and managing tacit product line requirements knowledge. // In Second International Workshop on Managing Requirements Knowledge (MARK). IEEE, 2009, pp. 60-64. DOI: 10.1109/mark.2009.8

[18] Stone, A.; Sawyer, P. Exposing Tacit Knowledge via PreRequirements Tracing. // In $14^{\text {th }}$ IEEE International Requirements Engineering Conference (RE'06), IEEE, 2006, pp. 353-354. DOI: 10.1109/RE.2006.22

[19] Pittke, F.; Leopold, H.; Mendling, J. Automatic detection and resolution of lexical ambiguity in process models. // IEEE Transactions on Software Engineering. 41, 6(2015), pp. 526-544. DOI: 10.1109/TSE.2015.2396895

[20] Nguyen, T. H.; Vo, B. Q.; Lumpe, M.; Grundy, J. REInDetector: a framework for knowledge-based requirements engineering. // In Proceedings of the 27th IEEE/ACM International Conference on Automated Software Engineering. ACM, 2012, pp. 386-389. DOl: 10.1145/2351676.2351754

[21] Gleich, B.; Creighton, O.; Kof, L. Ambiguity detection: Towards a tool explaining ambiguity sources. // In International Working Conference on Requirements Engineering: Foundation for Software Quality. Springer Berlin Heidelberg, 2010, pp. 218-232.

[22] Kiyavitskaya, N.; Zeni, N.; Mich, L.; Berry, D. M. Requirements for tools for ambiguity identification and measurement in natural language requirements specifications. // Requirements Engineering. 13, 3(2008), pp. 207-239. DOI: 10.1007/s00766-008-0063-7

[23] Dreyer, H.; Wynn, M. G.; Bown, G. R. Tacit and Explicit Knowledge in Software Development Projects: Towards a Conceptual Framework for Analysis. // In eKnow $20157^{\text {th }}$ International Conference on Information, Process and Knowledge Management. ThinkMind, 2015, No. A, pp. 4952.

[24] Quispe, A.; Marques, M.; Silvestre, L.; Ochoa, S. F.; Robbes, R. Requirements engineering practices in very small software enterprises: A diagnostic study. // In XXIX International Conference of the Chilean Computer Science Society (SCCC). IEEE, 2010, pp. 81-87. DOI: 10.1109/sccc.2010.35

[25] Jantunen, S. Exploring software engineering practices in small and medium-sized organisations. // Proceedings of the 2010 ICSE Workshop on Cooperative and Human Aspects of Software Engineering (CHASE '10), 2010, pp. 96-101. DOI: 10.1145/1833310.1833326

[26] Aranda, J.; Easterbrook, S.; Wilson, G. Requirements in the wild: How small companies do it. // In $15^{\text {th }}$ IEEE International Requirements Engineering Conference (RE 2007). IEEE, 2007, pp. 39-48. DOI: 10.1109/RE.2007.54

[27] Kauppinen, M.; Vartiainen, M.; Kontio, J.; Kujala, S.; Sulonen, R. Implementing requirements engineering processes throughout organisations: success factors and challenges. // Information and Software Technology. 46, 14(2004), pp. 937-953. DOI: 10.1016/j.infsof.2004.04.002

[28] Nikula, U.; Sajaniemi, J.; Kälviäinen, H. A State-of-thepractice Survey on Requirements Engineering in Small-and Medium-sized Enterprises. // TBRC Research Report 1, Lappeenranta University of Technology, Finland, 2000.

[29] Lubars, M.; Potts, C.; Richter, C. A Review of the State of the Practice in Requirements Modeling. // In Proceedings of IEEE International Symposium on Requirements Engineering. IEEE, 1993, pp. 2-14.
[30] Kamsties, E.; Hörmann, K.; Schlich, M. Requirements engineering in small and medium enterprises. // Requirements engineering. 3, 2(1998), pp. 84-90. DOI: 10.1007/BF02919967

[31] Matulevičius, R. Survey of Requirements Engineering Practice in Lithuanian Software Development Companies. // In Information Systems Development. Springer US, 2005, pp. 327-339.

[32] Solemon, B.; Sahibuddin, S.; Ghani, A. A. A. Adoption of requirements engineering practices in Malaysian software development companies. // In International Conference on Advanced Software Engineering and Its Applications. Springer Berlin Heidelberg, 2010, pp. 141-150.

[33] Gorschek, T.; Svahnberg, M. Requirements experience in practice: Studies of six companies. // Engineering and Managing Software Requirements. Springer Berlin Heidelberg. (2005), pp. 405-426.

[34] Rech, J.; Ras, E.; Decker, B. Intelligent assistance in German software development: A survey. // IEEE software. 24, 4(2007), pp. 72-79. DOI: 10.1109/MS.2007.110

[35] Dukic, B.; Bara, D.; Dukic, S. Impact of right-time business intelligence tools on efficiency in decision making. // Tehnicki glasnik. 10, 1-2(2016), pp. 1-8

[36] Thörn, C. Current state and potential of variability management practices in software-intensive SMEs: Results from a regional industrial survey. // Information and Software Technology. 52, 4(2010), pp. 411-421. DOI: 10.1016/j.infsof.2009.10.009

[37] Ihme, T.; Pikkarainen, M.; Teppola, S.; Kääriäinen, J.; Biot, O. Challenges and industry practices for managing software variability in small and medium sized enterprises. // Empirical Software Engineering. 19, 4(2014), pp. 11441168. DOI: $10.1007 /$ s10664-013-9253-0

[38] Implicit Requirements Online Survey https://sites.google.com/a/covenantuniversity.edu.ng/resurv ey1/ (30/03/2014)

[39] Gliem, R. R.; Gliem, J. A. Calculating, interpreting, and reporting Cronbach's alpha reliability coefficient for Likerttype scales. // In Proceeding of Midwest Research-toPractice Conference in Adult, Continuing, and Community Education, 2003, pp. 82-88.

[40] Wohlin, C.; Runeson, P.; Höst, M.; Ohlsson, M. C.; Regnell, B.; Wesslén, A. Experimentation in software engineering. // Springer Science \& Business Media, 2012. DOI: 10.1007/978-3-642-29044-2

\section{Authors' addresses}

Onyeka Emebo

Covenant University PMB 1023 Ota, Nigeria

onye.emebo@covenantuniversity.edu.ng

Olawande Daramola, Associate Professor,

Corresponding Author

Covenant University

PMB 1023 Ota, Nigeria

olawande.daramola@covenantuniversity.edu.ng

Charles Ayo, Professor

Covenant University

PMB 1023 Ota, Nigeria

charles.ayo@covenantuniversity.edu.ng 